\title{
OSCILLATION OF EVEN ORDER NONLINEAR NEUTRAL DIFFERENTIAL EQUATIONS WITH DAMPING
}

\author{
Y. ŞAHINER YILMAZ AND A. ZAFER
}

Abstract. Oscillation criteria for even order differential equations of the following form

$$
z^{(n)}(t)+p(t) \phi\left(z^{(n-1)}(t)\right)+q(t)|x(\sigma(t))|^{\alpha} \operatorname{sgn}[x(\sigma(t))]=0,
$$

where

$$
z(t)=x(t)+a(t) x(\tau(t)), \quad \alpha>0, \quad \text { and } n \text { is even }
$$

are obtained via comparison with second order differential inequalities. It is shown that existence of no eventually positive solution of a certain second order delay differential inequality is sufficient for every solution $x(t)$ of the above equation to be oscillatory.

Mathematics subject classification (1991): 34K15; 34K40.

Key words and phrases: Oscillation, damping term, neutral equation.

\section{REFERENCES}

[1] D. D. BAINOV AND D. P. Mishev, Oscillation theory for neutral equations with delay, Adam Hilger IOP Publisching Ltd., 1991.

[2] R. S. DAHIYA AND A. ZAFER, Asymptotic behavior and oscillation in higher order nonlinear differential equations with retarded arguments, Acta Math. Hungar., 76 (3) (1997), 257-266.

[3] S. R. GRACE AND B. S. LALLI, Oscillation theorems for $n$-th order delay differential equations, J. Math. Anal. Appl., 91 (1983), 352-366.

[4] S. R. GRACE, B. S. LALLI AND C. C. YEH, Oscillation theorems for nonlinear second order differential equations with a nonlinear damping term, SIAM J. Math. Anal., 15 (6) (1984), 1082-1093.

[5] S. R. GRACE, Oscillatory and asymptotic behavior of delay differential equations with a nonlinear damping, J. Math. Anal. Appl., 168 (1992), 306-318.

[6] , On the oscillation of certain functional differential equations, J. Math. Anal. Appl., 194 (1995), 304-318.

[7] J. R. GRAEF AND P. W. SPIKES, Some asymptotic properties of solutions of a neutral delay equation with an oscillatory coefficient, Canad. Math. Bull., 36 (3) (1993), 263-272.

[8] I. T. KIGURADZE, Oscillation properties of solutions of certain ordinary differential equations, Dok1. Akad. Nauk SSR, (1962), 33-36.

[9] - On the oscillation of solutions of the equation $d^{m} u / d t^{m}+a(t)|u|^{n} \operatorname{sgn} u=0$, Mat. Sb., 65 (1964), 172-187. [Russian]

[10] M. NAITO, Oscillation theorems for a damped nonlinear differential equation, Proc. Japan Acad., 50 (1974), 104-108.

[11] T. KUSANO, Oscillation of even order linear functional differential equations with deviating arguments of mixed type, J. Math. Anal. Appl., 98 (1984), 341-347.

[12] A. H. NASR, Necessary and sufficient conditions for the oscillation of forced second order differential equations with delayed argument, J. Math. Anal. Appl., 212 (1997), 51-59. 
[13] M. RŪŽIČKOVÁ AND E.S̆PÁNIKOVÁ, Oscillation theorems for neutral differential equations with the quasi-derivatives, Archivum Mathematicum, 30 (1994), 293-300.

[14] A. ZAFER AND R. S. DAHIYA, Oscillation of solutions of arbitrary order neutral functional differential equations with forcing terms, Proceedings of the First World Congress of Nonlinear Analysts, (1996), 1977-1987.

[15] A. ZAFER, Oscillation criteria for even order neutral differential equations, Appl. Math. Lett., to appear. 